\title{
PENGARUH KUALITAS PELAYANAN PAJAK DAN PENGETAHUAN WAJIB PAJAK TERHADAP KEPATUHAN WAJIB PAJAK ORANG PRIBADI DI KELURAHAN KLEAK KECAMATAN MALALAYANG KOTA MANADO
}

\author{
Kilapong G. Ester ${ }^{1}$, Grace B. Nangoi ${ }^{2}$, Stanly W. Alexander ${ }^{3}$ \\ ${ }^{1,2,3}$ Fakultas Ekonomi dan Bisnis, Jurusan Akuntansi, Universitas Sam Ratulangi, J1.Kampus Bahu, Manado \\ 95115, Indonesia \\ E-mail: gisellaester@yahoo.com
}

\begin{abstract}
Taxpayer compliance is a law-abiding behavior. Conceptually, compliance is defined by an attempt to comply with the rules of law by a person or organization. Some factors that cause low compliance of taxpayers, among others, public dissatisfaction with public service and taxpayer knowledge of tax regulations.This study aims to determine the effect of tax service quality and tax payer knowledge on individual tax payer compliance in Kleak urban village. This research used primary data with distributing questionnaire. Questionnaires were distributed as many as 40 pieces to individual tax payer in Kleak urban village. Research sampling were taken by purposive sampling. Data were analyzed by using multiple linear regression analysis with SPSS 17 program. The results of this study indicate that the Tax Service Quality has no significant effect on individual tax payer compliance. And Tax payers Knowledge has a significant effect on individual tax payer compliance in Kleak urban village.
\end{abstract}

Keywords: Tax Service Quality, Tax Payers Knowledge, Tax Compliance.

\section{PENDAHULUAN}

Pajak merupakan sumber penerimaan negara dalam menopang pembiayaan pembangunan yang bersumber dari dalam negeri. Permasalahan untuk menaikkan tingkat kepatuhan wajib pajak merupakan persoalan klasik yang seolah tidak pernah selesai. Tentu perlu untuk diketahui apa upaya yang sepatutnya dilakukan dalam rangka menaikkan tingkat kepatuhan, kerelaan serta antusiasme dari wajib pajak guna membayar pajak.

Besar-kecilnya pajak akan menentukan kapasitas anggaran negara dalam membiayai pengeluaran negara, baik untuk pembiayaan pembangunan maupun untuk pembiayaan anggaran rutin. Oleh karena itu pajak memiliki peran yang sangat penting dalam penerimaan negara sampai saat ini.

Dalam upaya untuk meningkatkan penerimaan negara, maka Direktorat Jendral Pajak (DJP) melakukan reformasi perpajakan secara menyeluruh. Begitu besarnya peran pajak dalam penerimaan negara, pemerintah sudah seharusnya memaksimalkan pendapatan negara dari sektor pajak. Salah satu cara pemerintah untuk memaksimalkan pendapatan negara dari sektor pajak yaitu mulai diberlakukannya sistem pemungutuan pajak self assessment system sejak reformasi perpajakan pada tahun 1983 sebagai pengganti dari official assessment system (Kusuma, 2016). Kendati demikian ada kelemahan dalam penerapan self assesment system yaitu, bahwa tidak semua wajib pajak yang tentunya mengerti mengenai aturan perpajakan yang berlaku di Indonesia yang dinamikanya terus terjadi. Di sisi lain self assessment system secara tanggung jawab akan membuat wajib pajak wajib memahami ketentuan yang berlaku dalam aturan perpajakan Indonesia (Pertama, 2015).

Kepatuhan pajak di Indonesia masih rendah, baru 30 persen wajib pajak yang membayar pajak. Jika dibandingkan dengan kepatuhan pembayaran Malaysia yang sudah 
mencapai 80 persen wajib pajak terdaftar, tentu kinerja pajak Indonesia tertinggal jauh. Tidak realistis membandingkan dengan Indonesia dengan keberhasilan Malaysia sebelum melihat kondisi administrasi perpajakan di Malaysia (Suryana, 2012).

Beberapa faktor yang menyebabkan rendahnya kepatuhan wajib pajak antara lain ketidakpuasan masyarakat terhadap pelayanan publik, pembangunan infrastruktur yang tidak merata, dan banyaknya kasus korupsi yang dilakukan pejabat tinggi. Dalam sesi tanya jawab pada beberapa kegiatan sosialisasi perpajakan yang dilakukan, salah satu penyebabnya adalah masyarakat kurang merasakan manfaat dari pajak yang telah dibayar, misalnya masih banyaknya jalan yang rusak dan sarana publik yang tidak memadai serta kasus korupsi yang kerap mendera pejabat eksekutif pemerintahan baik pusat ataupun daerah (Akbar, dkk 2015).

Salah satu upaya dalam peningkatan kepatuhan wajib pajak adalah memberikan pelayanan yang baik kepada wajib pajak. Peningkatan kualitas dan kuantitas pelayanan diharapkan dapat meningkatkan kepuasan kepada wajib pajak sehingga wajib pajak akan meningkatkan kepatuhan dalam melaksanakan kewajibannya membayar pajak (Kusuma, 2016). Pada kenyataannya masih ada wajib pajak merasa menemui hambatan dalam proses pelayanan yang diberikan oleh aparatur perpajakan yaitu petugas yang lambat, tidak ramah, berbelit-belit, menunggu terlalu lama, kantor dan layanan kurang nyaman, fasilitas yang tidak memadai sehingga menimbulkan keluhan, komplain, dan enggannya mereka menyelesaikan urusan perpajakannya, dan pada gilirannya nanti berakibat pada tumbuhnya sikap tidak patuh dalam melaksanakan kewajiban perpajakan (Hidayatulloh, 2013).

Di samping faktor-faktor sebagaimana disebutkan di atas, maka faktor lainnya sehingga kesadaran masyarakat membayar pajak masih belum mencapai tingkat sebagaimana yang diharapkan yaitu karena ketidak mengertian masyarakat tentang apa dan bagaimana pajak serta repot menghitung dan melaporkannya (Susanto, 2012). Palil (2005) menemukan bahwa pengetahuan wajib pajak tentang pajak yang baik akan dapat memperkecil adanya tax evation. Menurut Kassipillai, bahwa pengetahuan tentang pajak merupakan hal yang sangat penting bagi berjalannya self assessment system. Pengetahuan tentang peraturan pajak akan mempengaruhi sikap wajib pajak terhadap kewajiban pajak (Fermatasari, 2013). Berdasarkan latar belakang penelitian yang telah di kemukakan sebelumnya, maka dapat dirumuskan masalah antara lain : (1) apakah kualitas pelayanan pajak berpengaruh terhadap kepatuhan wajib pajak orang pribadi di Kelurahan Kleak?; (2) apakah pengetahuan wajib pajak berpengaruh terhadap kepatuhan wajib pajak orang pribadi di Kelurahan Kleak?

Tujuan peneliti dalam penelitian ini adalah : (1) untuk mengetahui pengaruh kualitas pelayanan pajak terhadap kepatuhan wajib pajak orang pribadi di Kelurahan Kleak; (2) untuk mengetahui pengaruh pengetahuan wajib pajak terhadap kepatuhan wajib pajak orang pribadi di Kelurahan Kleak.

\section{TINJAUAN PUSTAKA \\ 2.1 Pengertian Pajak}

Menurut P.J.A. Adriani pajak adalah Pajak adalah iuran masyarakat kepada negara (yang dapat dipaksakan) yang terutang oleh yang wajib membayarnya menurut peraturanperaturan umum (undang-undang) dengan tidak mendapat prestasi kembali yang langsung dapat ditunjuk dan yang gunanya adalah untuk membiayai pengeluaran-pengeluaran umum berhubung tugas negara untuk menyelenggarakan pemerintahan (Sari, 2013:34).

\subsection{Kualitas Pelayanan Pajak}

Menurut Lan (2003) kualitas pelayanan dapat diartikan sebagai sesuatu yang berhubungan dengan terpenuhinya harapan atau kebutuhan pelanggan, di mana pelayanan dikatakan berkualitas apabila dapat menyediakan produk atau jasa (pelayanan) sesuai dengan kebutuhan dan harapan pelanggan (Dewi, 2013). 


\subsubsection{Dimensi Kualitas Pelayanan}

Terdapat lima dimensi kualitas pelayanan menurut parasuraman dalam penelitian Juventia (2014) yaitu:

1. Tangibles, bukti fisik yaitu kemampuan perusahaan dalam menunjukan eksistensinya kepada pihak eksternal. Yang dimaksud bahwa penampilan dan kemampuan sarana dan prasarana fisik perusahaan dan keadaan lingkungan sekitarnya adalah bukti nyata dan pelayanan yang diberikan.

2. Reliability, atau kehandalan yaitu kemampuan perusahaan untuk memberikan pelayanan sesuai yang dijanjikan secara akurat dan terpercaya.

3. Responsiveness, atau daya tanggap yaitu suatu kemampuan untuk membantu dan memberikan pelayanan cepat dan tepat kepada pelanggan, dengan penyampaian informasi yang jelas.

4. Assurance, atau jaminan dan kepastian yaitu pengetahuan, kesopansantunan, dan kemampuan para pegawai perusahaan untuk menumbuhkan rasa percaya para pelanggan kepada perusahaan. Terdiri dari beberapa komponen antara lain komunikasi, kredibilitas, keamanan, kompetensi dan sopan santun.

5. Empathy, yaitu memberikan perhatian yang tulus dan bersifat individual atau pribadi yang diberikan kepada para pelanggan dengan berupaya memahami keinginan pelanggan.

\subsection{Pengetahuan Wajib Pajak}

Menurut Carolina, dalam penelitian (Caroko dkk. 2015) Pengetahuan Pajak adalah informasi pajak yang dapat digunakan wajib pajak sebagai dasar untuk bertindak, mengambil keputusan, dan untuk menempuh arah atau strategi tertentu sehubungan dengan pelaksanaan hak dan kewajibannya di bidang perpajakan ".

Didalam faktor-faktor pengetahuan wajib pajak menurut Taslim (2007) sebagaimana dikutip dalam penelitian Sara (2014) tinggi rendahnya pengetahuan wajib pajak dapat diukur dengan:

1. Pemahaman prosedur atau cara pengisian SPT

2. Pemahaman batas waktu pelaporan SPT

3. Pemahaman sanksi perpajakan dan administrasi

\subsection{Kepatuhan Wajib Pajak}

Kepatuhan wajib pajak adalah usaha untuk memenuhi segala kewajibannya dengan sadar dan atas dasar kemauannya sendiri, hal ini menunjukkan bahwa wajib pajak telah bersikap baik terhadap segala kewajibannnya (Prabawa \& Noviari, 2012). Adanya kepatuhan maka secara tidak langsung penerimaan pajak akan berjalan dengan lancar karena kepatuhan wajib pajak telah menunjukan bahwa wajib pajak telah melaksanakan kewajiban perpajakannya dengan baik.

Menurut Norman D. Nowak dalam Irmawati (2015) Kepatuhan perpajakan sebagai suatu iklim kepatuhan dan kesadaran pemenuhan kewajiban perpajakan tercemin dalam situasi sebagai berikut:

1. Wajib pajak paham atau berusaha untuk memahami semua ketentuan peraturan perundang-undangan perpajakan.

2. Mengisi formulir pajak dengan lengkap dan jelas.

3. Menghitung jumlah pajak yang terutang dengan benar.

4. Membayar pajak yang terutang tepat pada waktunya.

\section{METODE PENELITIAN}

\subsection{Jenis \& Sumber Data}

Jenis Penelitian yang digunakan adalah penelitian kuantitatif dengan metode penelitian asosiatif dengan bentuk pola hubungan yaitu hubungan kausal. Jenis data penelitian yang digunakan 
yaitu data kualitatif dan data kuantitatif. Sumber data di dalam penelitian ini adalah data primer. Sumber data primer dalam penelitian ini adalah diperoleh langsung dari wajib pajak orang pribadi yang ada di Manado. Data ini berupa kuesioner yang telah diisi oleh para wajib pajak orang pribadi yang menjadi responden terpilih dalam penelitian ini.

\subsection{Populasi dan Sampel}

Populasi pada penelitian ini adalah wajib pajak orang pribadi di Kelurahan Kleak Kota Manado yang terdaftar pada KPP Pratama Manado.

Metode pengambilan sampel dilakukan dengan Sampling Purposive, Teknik ini merupakan salah satu teknik Nonprobability Sampling. Sampel dalam penelitian ini adalah wajib pajak orang pribadi di kelurahan kleak sebanyak 40 responden, dengan cara pengambilan sampel menggunakan rumus slovin sebagai berikut :

$$
\mathrm{n}=\frac{\mathrm{N}}{1+\mathrm{Ne}^{2}}
$$

\subsection{Metode Analisis}

Dalam penelitian akan dianalisis dengan menggunakan analisis statistik yang meliputi analisis deskriptif, uji kualitas data (uji validitas dan reliabilitas), uji asumsi klasik (uji normalitas, uji multikolonieritas, dan uji heteroskedastisitas), dan uji hipotesis.

\section{HASIL PENELITIAN DAN PEMBAHASAN}

\subsection{Hasil Penelitian}

\section{1) Uji Validitas dan Uji Reliabilitas}

Berdasarkan nilai koefisien korelasi dengan mengunakan bantuan SPSS 17.0 diperoleh hasil bahwa variabel pada penelitian ini adalah valid dan reliabel. Hasil tersebut dibuktikan dari $r_{\text {hitung }}$ lebih besar dari $r_{\text {tabel }}$ yaitu lebih dari 0.312 dan nilai alpha lebih besar 0.60.

2) Uji Asumsi Klasik

\section{a. Uji Normalitas}

Uji Normalitas dalam penelitian ini dilakukan dengan kolmogrov-smirnov test dan metode grafik ( $P-P$ Plot). Hasil tersebut dibuktikan sebagai berikut:

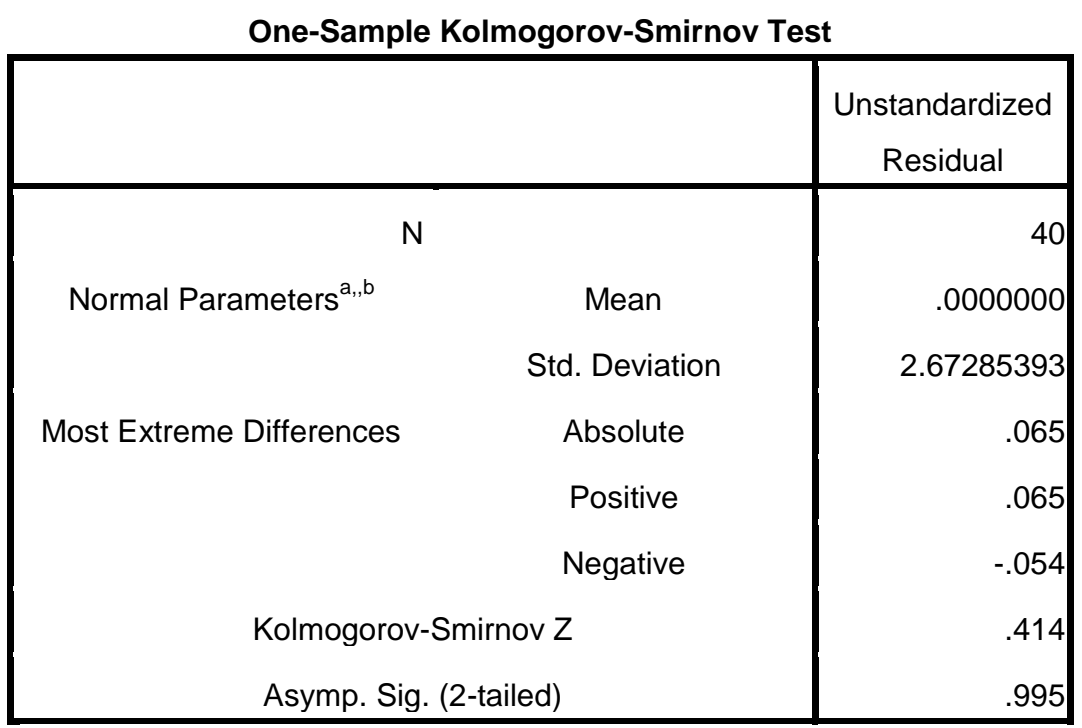

a. Test distribution is Normal.

b. Calculated from data.

Menunjukkan pada Kolmogrov smirnov dapat diketahui bahwa nilai signifikan untuk variabel lebih besar dari 0.05 yaitu 0.995. maka dapat disimpulkan data berdistribusi normal. 


\section{Gambar Uji Normalitas P-P Plot}

\section{Normal P-P Plot of Regression Standardized Residual}

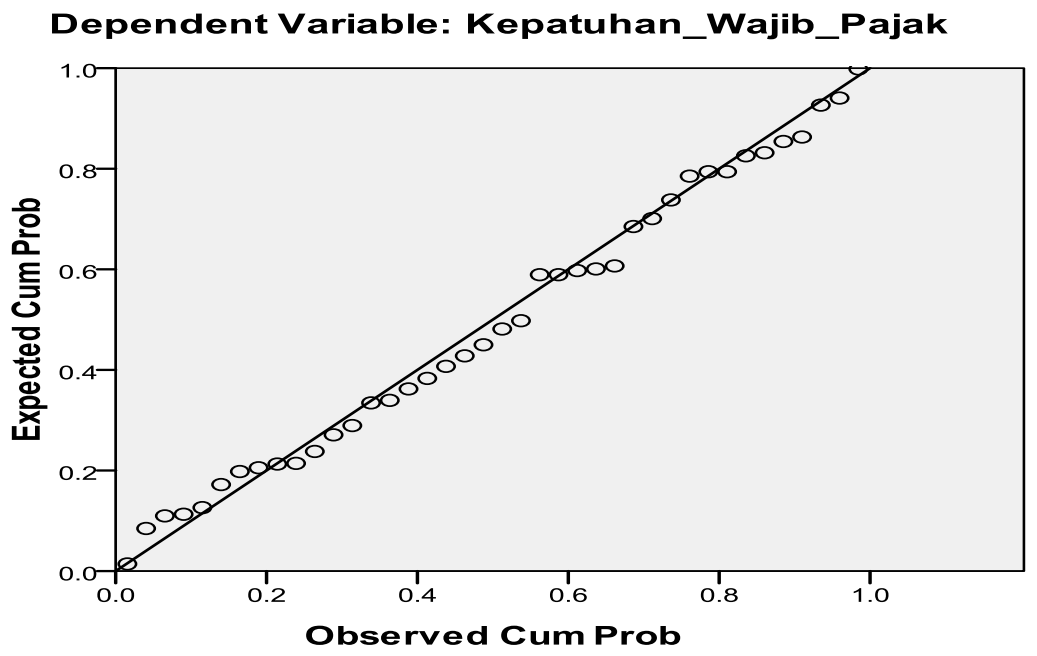

Menunjukkan dapat dilihat bahwa titik-titik menyebar di sekitar garis dan mengikuti garis diagonal. Oleh karena itu, model regresi memenuhi asumsi normalitas.

\section{b. Uji Multikolinearitas}

\begin{tabular}{|c|c|c|}
\hline Variabel & Tolerance & VIF \\
\hline Kualitas Pelayanan Pajak & 0,834 & 1,199 \\
\hline Pengetahuan Wajib Pajak & 0,834 & 1,199 \\
\hline
\end{tabular}

Berdasarkan tabel di atas dapat dilihat bahwa nilai tolerance dari variabel independen lebih dari 0.1 dan nilai VIF kurang dari 10. Hal ini menunjukkan bahwa tidak terjadi multikolonieritas.

\section{c. Uji Heteroskedastisitas}

Scatterplot

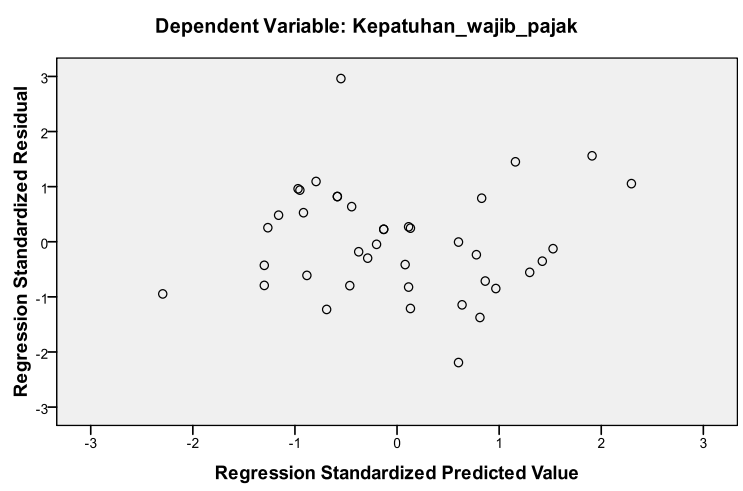


Berdasarkan gambar di atas, maka tidak terjadi heteroskedastisitas karena titik-titik menyebar di atas dan di bawah nilai angka nol (0) pada sumbu Y dan tidak membentuk pola.

\section{3) Uji Hipotesis}

Coefficients $^{\mathrm{a}}$

\begin{tabular}{|c|c|c|c|c|c|}
\hline \multirow[b]{2}{*}{ Model } & \multicolumn{2}{|c|}{ Unstandardized Coefficients } & \multirow{2}{*}{$\begin{array}{c}\text { Standardized } \\
\text { Coefficients }\end{array}$} & \multirow[b]{2}{*}{$\mathrm{T}$} & \multirow[b]{2}{*}{ Sig. } \\
\hline & $B$ & Std. Error & & & \\
\hline (Constant) & 5.957 & 5.209 & & 1.144 & .260 \\
\hline Kualitas_pelayanan_pajak & .126 & .091 & .148 & 1.380 & .176 \\
\hline Pengetahuan_wajib_pajak & .690 & .101 & .731 & 6.807 & .000 \\
\hline
\end{tabular}

a. Dependent Variable: Kepatuhan_wajib_pajak

Berdasarkan hasil uji t pada tabel diatas, nilai sig, untuk pengaruh Kualitas pelayanan pajak (X1) Terhadap Y adalah sebesar $0.176>0.05$ dan nilai t hitung $1.380<\mathrm{t}$ tabel 2.026, sehingga dapat disimpulkan bahwa $\mathrm{H} 1$ ditolak yang berarti tidak terdapat pengaruh $\mathrm{X} 1$ terhadap Y.

Nilai sig. untuk pengaruh pengetahuan wajib pajak (X2) terhadap Y adalah sebesar $0.000<0.005$ dan $\mathrm{t}$ hitung 6.807>2.026, sehingga dapat disimpulkan bahwa $\mathrm{H} 2$ diterima berarti terdapat pengaruh $\mathrm{X} 2$ terhadap $\mathrm{Y}$.

\subsection{Pembahasan}

\section{1) Pengaruh Kualitas Pelayanan Pajak terhadap Kepatuhan Wajib Pajak}

Berdasarkan hasil uji t menunjukkan bahwa nilai t hitung lebih kecil dari nilai t tabel $(1.380<2.026)$ dan nilai signifikansi yang lebih besar daripada nilai signifikan 5\% (0.176 > 0.05). Hal ini menunjukkan bahwa kualitas pelayanan pajak tidak mempunyai pengaruh terhadap kepatuhan wajib pajak. Pelayanan pajak yang baik dari instansi pajak merupakan hal yang penting untuk menarik perhatian wajib pajak, wajib pajak berhak mendapatkan pelayanan yang baik tentunya dan dapat membuat tingkat kepatuhan wajib pajak meningkat. Mayoritas responden telah memberikan tanggapan yang baik pada kuesioner untuk kualitas pelayanan pajak di KPP Pratama Manado.

Hasil penelitian ini mendukung hasil penelitian (Dewi, 2015) yang menyatakan bahwa Kualitas pelayanan tidak berpengaruh positif terhadap kepatuhan wajib pajak orang pribadi.

\section{2) Pengaruh Pengetahuan Wajib Pajak terhadap Kepatuhan wajib pajak}

Hasil perhitungan regresi menunjukkan nilai koefisien regresi positif dari variabel pengetahuan wajib pajak dengan kepatuhan wajib pajak. Uji t menunjukkan bahwa nilai $t$ hitung lebih besar daripada nilai t tabel $(6.807>2.026)$ dan nilai signifikansi yang lebih kecil daripada nilai signifikan $5 \%(0.000<0.005)$. Hal ini menunjukkan bahwa pengetahuan wajib pajak mempunyai pengaruh terhadap kepatuhan wajib pajak.

Pengetahuan yang diperoleh wajib pajak sebagian besar berasal dari petugas pajak. Tingginya tingkat pengetahuan wajib pajak mengenai aturan dan ketentuan perpajakan dapat meningkatkan kepatuhan wajib pajak. Berdasarkan hasil penelitian ini kepatuhan wajib pajak dipengaruhi oleh pengetahuan wajib pajak secara parsial. Dimana hasil penelitian ini sejalan dengan (Harlina, 2016) yaitu Pengetahuan Pajak berpengaruh signifikan terhadap kepatuhan wajib pajak secara parsial. 


\section{KESIMPULAN DAN SARAN}

\section{Kesimpulan}

Berdasarkan hasil penelitian yang telah diuraikan sebelumnya, maka dapat diambil kesimpulan sebagai berikut:

1. Kualitas pelayanan pajak tidak berpengaruh terhadap kepatuhan wajib pajak orang pribadi di Kelurahan Kleak. Meskipun pelayanan yang baik diberikan, itu tidak membuat wajib pajak untuk patuh dalam menyelesaikan kewajiban perpajakannya. Dapat diketahui untuk meningkatkan kepatuhan wajib pajak tidak cukup dengan pelayanan yang baik diberikan, melainkan masih perlu adanya faktor-faktor pendorong lain untuk dapat meningkatkan kepatuhan wajib pajak.

2. Pengetahuan wajib pajak berpengaruh terhadap kepatuhan wajib pajak orang pribadi di Kelurahan Kleak. Hal ini menunjukkan bahwa semakin tinggi pengetahuan wajib pajak mengenai perpajakan maka semakin tinggi pula kepatuhan wajib pajak.

\section{Saran}

Berdasarkan kesimpulan di atas diharapkan penelitian selanjutnya dapat menyajikan hasil penelitian yang berkualitas dengan adanya saran-saran mengenai beberapa hal :

1.Untuk penelitian selanjutnya bisa menggunakan sampel yang lebih banyak lagi, dibandingkan penelitian ini, agar hasil yang didapatkan bisa lebih akurat.

2.Bagi Pihak KPP Pratama, Perlu adanya peningkatan pengetahuan perpajakan masyarakat melalui pendidikan perpajakan, dan harus lebih rajin lagi dalam memberikan penyuluhan kepada wajib pajak agar pengetahuan wajib pajak meningkat dan makin sadar melaksanakan hak dan kewajibannya.

3.Penelitian selanjutnya dapat menggunakan variabel lainnya sehingga untuk selanjutnya dapat ditemukan variabel baru yang akan mempengaruhi kepatuhan wajib pajak.

\section{DAFTAR PUSTAKA}

Akbar Iman Nur, Dwi Atmanto, Amirudin Jauhari. 2015. Pengaruh Persepsi Wajib Pajak Orang Pribadi Terhadap Pelaksanaan Self Assessment System (Studi Kasus Pada Wajib Pajak Orang Pribadi di Kantor Pelayanan Pratama Batu). Jurnal Perpajakan (JEJAK) Vol.7 No. 12015.

Caroko Bayu, Heru Susilo, Zahroh Z.A. 2015 . Pengaruh Pengetahuan Perpajakan, Kualitas Pelayanan Pajak dan Sanksi Pajak Terhadap Motivasi Wajib Pajak Orang Pribadi Dalam Membayar Pajak. Fakultas Ilmu Administrasi Program Studi Perpajakan Universitas Brawijaya.

Dewi, Fransisca Novieta Afsari. 2013 . Pengaruh Pengetahuan Pajak, Kualitas Pelayanan dan Sanksi Perpajakan Terhadap Kepatuhan Wajib Pajak Orang Pribadi (Studi Empiris di Kantor Pelayanan Pajak (KPP) Pratama Mataram Barat). Skripsi. Yogyakarta: Fakultas Ekonomi Jurusan Akuntansi - Universitas Sanata Dharma.

Fermatasari, Dewi. 2013 . Pengaruh Pengetahuan Pajak dan Sanksi Pajak Terhadap Kepatuhan Wajib Pajak (Survey di Kantor Pelayanan Pajak Pratama Bandung Karees). Jurusan Akuntansi - Universitas Komputer Indonesia.

Hidayatulloh, Hilman Akbar . 2013 . Pengaruh Kualitas Pelayanan Pajak dan Pengetahuan Pajak Terhadap Kepatuhan Wajib Pajak (Survey pada KPP Pratama Bandung Cicadas). Skripsi. Bandung: Jurusan Akuntansi - Universitas Komputer Indonesia.

Irmawati, Agnes Sophia . 2015 . Pengaruh Kesadaran Wajib Pajak, Sanksi Perpajakan, dan Pemahaman Perpajakan Terhadap Kepatuhan Wajib Pajak (Studi Kasus Kantor 
Pelayanan Pajak Pratama Jakarta Cakung Satu). Skripsi. Jakarta: Fakultas Ekonomi Jurusan Akuntansi - Universitas Darma Persada.

Juventia, Nadia. 2014. Pengaruh Kualitas Pelayanan dan Pengetahuan Pajak Terhadap Tingkat Kepatuhan Wajib Pajak Orang Pribadi (Studi Survei pada Kantor Pelayanan Pajak Pratama Bandung Karees). Skripsi. Bandung: Fakultas Ekonomi - Universitas Widyatama.

Kusuma, Kartika Candra. 2016 . Pengaruh Kualitas Pelayanan Pajak, Pemahaman Peraturan Perpajakan Serta Sanksi Perpajakan Terhadap Kepatuhan Wajib Pajak Orang Pribadi Dalam Membayar Pajak Tahun 2014 (Studi Kasus pada Wajib Pajak Yang Terdaftar di Kantor Pelayanan Penyuluhan dan Konsultasi Perpajakan Wonosobo). Skripsi. Yogyakarta: Fakultas Ekonomi Program Studi Akuntansi Universitas Negeri Yogyakarta.

Pertama, 2015. Problematika Penerapan Sistem Perpajakan Indonesia. http://www.kompasiana.com/adamdosapertama/problematika-penerapan-sistemperpajakan-indonesia 55123ef08133114254bc6364. Diakses pada 11 Maret 2017

Prabawa Made Adi Mertha, Naniek Noviari. 2012 . Pengaruh Kualitas Pelayanan dan Sikap Terhadap Kepatuhan Pelaporan Wajib Pajak Orang Pribadi di KPP Badung Utara. Fakultas Ekonomi - Universitas Udayana Denpasar (Unud) Bali.

Sara, Lusiana Jayanti. 2014 . Pengaruh Pengetahuan Pajak dan Sistem Administrasi Perpajakan Modern Terhadap Kepatuhan Wajib Pajak. Fakultas Ekonomi Program Studi Akuntansi - Universitas Komputer Indonesia.

Sari, Diana. 2013 . Konsep Dasar Perpajakan. Bandung, PT Refika Aditama.

Suryana, Anandita Budi. 2012. Mengerek Kepatuhan Wajib Pajak. http://www.pajak.go.id/contrnt/article/mengerek-kepatuhan-wajib-pajak. Diakses 11 Maret 2017.

Susanto, Herry. 2012 . Membangun Kesadaran dan Kepedulian Sukarela Wajib Pajak. http://www.pajak.go.id/content/membangun-kesadaran-dan-kepedulian-sukarelawajib-pajak. Diakses 11 Maret 2017. 